\title{
Macroflocs, fine-grained sediment transports, and their longitudinal variations in the Ems Estuary
}

\author{
Wim van Leussen
}

Received: 13 November 2009 / Accepted: 25 January 2011 /Published online: 30 March 2011

(C) The Author(s) 2011. This article is published with open access at Springerlink.com

\begin{abstract}
Field measurements have been carried out to obtain more quantitative knowledge on the longitudinal distribution of the fine-grained sediment dynamics in the Ems Estuary. Both the short-term (time scale $<$ tidal period) and the long-term (tidally averaged) fine-grained sediment transports have been investigated. It is shown that the shortterm erosion/sedimentation cycles are most characteristic and are the building blocks for the ultimate long-term transports. Herein, the macroflocs play a key role. The macroflocs had sizes in the range of 200 to $700 \mu \mathrm{m}$, sometimes more than $1 \mathrm{~mm}$, and survived high current velocities. The settling velocities were in the range of 0.5 to $8 \mathrm{~mm} / \mathrm{s}$. Turbulence intensities and suspended sediment concentration are of utmost importance for the settling properties of the sediment, but the "flocculation ability" of the suspended sediment is shown to be of equal importance. The suspended sediment concentration is only important at low levels of turbulence. At high levels of turbulence, the limiting properties of turbulence dominate. It is demonstrated that the surface properties of the suspended sediment particles are of prime importance for the flocculation ability of the water/sediment mixture, as do the sizes of the
\end{abstract}

Responsible Editor: Susana B. Vinzon

W. van Leussen

Rijkswaterstaat Oost Nederland, Ministry of Infrastructure and Environment,

P.O. Box 9070, 6800 ED Arnhem, The Netherlands

e-mail:wim@vanleussen.com

W. van Leussen $(\triangle)$

Faculty of Management and Governance-CSTM, University of Twente,

P.O. Box 217, 7500 Enschede, The Netherlands

e-mail:w.vanleussen@utwente.nl resuspended microflocs. Special attention is given to the longitudinal distribution of the sizes and settling properties of the macroflocs as well as of the sediment transports. The flocculation ability was shown to vary almost one order of magnitude along the estuary. These higher flocculation abilities in the direction of higher salinities are responsible for the increase of the sizes of the macroflocs in the seaward direction. Therefore, notwithstanding the low suspended sediment concentrations at the seaward boundary of the Ems Estuary, large macroflocs and corresponding high settling velocities were observed in this area. It explains that, in the Ems Estuary, no distinct effect was determined of the suspended sediment concentration on the settling properties of the suspended macroflocs.

Keywords Cohesive sediment · Ems Estuary · Macroflocs · Flocculation ability - Erosion/sedimentation cycles .

Fine-grained sediment transports

\section{Introduction}

Characteristic behavior of fine sediment can be observed in estuaries. Under influence of the tide, the fine-grained sediment is moving forward and backward, participating in a step-wise process of deposition and resuspension. The additional effects of river discharge, waves, and biota make this process quite complex. Examples can be found in many estuaries, such as the Seine Estuary (Le Hir et al. 2001), the Tamar Estuary (Tattersall et al. 2003), the Pearl River Estuary (Wai et al. 2004), the Gironde Estuary Doxaran et al. 2009), and the San Francisco Bay (Schoellhamer 2002).

It seems appropriate to distinguish between processes that are responsible for variations within the tidal period and long-term transports (time scale $>>$ tidal period). The 
last mentioned are the most interesting from an engineering point of view. However, the long-term horizontal transports cannot be understood without insight into the strongly variable short-term vertical transports within a tidal cycle.

To obtain more insight in both transports and on how they are interrelated, an extensive set of field measurements have been conducted in the Ems Estuary. It will be shown that fine-sediment behavior and the resulting transports are dominantly governed by "local phenomena", which means that the suspended sediment concentration is strongly influenced by the vertical movements of the sediment: erosion/sedimentation cycles. Special attention is given to the role of the macroflocs because it will be shown that they play a key role in these transports.

The paper starts with an overview of the extensive set of field measurements, giving special attention to the properties of the observed macroflocs and the erosion/sedimentation cycles. A series of laboratory experiments have been carried out to obtain quantitative information on the "flocculation ability" of the suspended sediment particles. For all these parameters, longitudinal variation along the estuarine axis is at the center of this research. Special attention is also given to the processes which are at the basis of these variations. The sections 6 and 7 concentrate on the longitudinal variations of the fine-grained sediment transports and of the macroflocs. It will be demonstrated that the macroflocs play an important role in the erosion/sedimentation cycles and that the erosion/sedimentation cycles are the building blocks for the ultimate long-term transports. All together they show strong variations along the estuarine axis, with the turbidity maximum as a singular area.

\section{Field measurements in the Ems Estuary}

The Ems Estuary is a partially mixed meso-tidal estuary in the north-eastern part of The Netherlands. It is situated at the boundary between The Netherlands and Germany, whereas the upper part of the estuary is within Germany. An overview is given in Fig. 1. This estuary is characterized by large areas of tidal flats, tidal channels, and salt marshes (De Jonge 1995; De Jonge and Brauer 2006). The mean tidal range at the sea boundary is $2.25 \mathrm{~m}$, and the river discharge varies from 25 to $380 \mathrm{~m}^{3} / \mathrm{s}$, with an annual mean value of $110 \mathrm{~m}^{3} / \mathrm{s}$. The sediment is primarily of marine origin.

The field measurements were conducted over a full tidal cycle at five locations along the main channel of the Ems Estuary:

\footnotetext{
- Ranselgat

- Oost Friesche Gaatje

- Emder Vaarwater
}

$\begin{array}{ll}\text { - } & \text { Turbidity maximum } \\ \text { - } & \text { River Ems (fresh water tidal area) }\end{array}$

These locations are indicated in Fig. 1. The Ranselgat area corresponds fairly well with the seaward boundary of the Ems estuary, while the River Ems location is situated in the fresh water part of the estuary. This means that the measurements cover the full range of salinities.

The measurements started half an hour before low water slack (LWS) and continued to half an hour after the following LWS. This means that measuring period of about $13.5 \mathrm{~h}$. In each location, two research vessels were positioned at a mutual distance of $1 \mathrm{~km}$, measured along the axis of the main channel.

Additional to the moored stations, simultaneously, measurements were conducted by a research vessel, which was floating with the tidal currents. The position of this water mass was followed by a float, consisting of a vertical tube with a length of about $4 \mathrm{~m}$. In shallow areas, a shorter float was applied. In principle, the main channel was followed. The floating vessel was moving in such a way that, about mid-way in the trajectory, it was in the vicinity of the moored vessels: once during flood and once during ebb (cf. Fig. 1).

At the moored stations, at each half-an-hour vertical profile, salinity, temperature, current velocity, and suspended sediment concentration were measured. At the floating vessel, only one vertical profile per hour was measured, at which time the vessel was anchored for about $15 \mathrm{~min}$. After that period, the vessel sailed again to the floating drifter. Also once an hour, about half an hour after the profile measurements, the sizes and settling velocities of the suspended macroflocs were determined. These properties of the macroflocs were determined by the underwater video system video in situ (VIS) (van Leussen and Cornelisse 1993a, 1996) at a depth of $2.80 \mathrm{~m}$ below the water surface. The principle is a relatively narrow vertical tube in which the settling flocs are captured carefully from the turbulent low, without disturbing them. Then, the settling of these flocs in still water is followed by a video camera, from which both the floc size and settling velocities can be obtained by analyzing the video recordings.

\section{Results of the field measurements}

The variations of the salinity during a tidal cycle are presented in Fig. 2a for five moored stations (St. nos. 1, 3, 5, 7, and 10). In the River Ems location (St. 1), the salinity is about constant $(\sim 0.2 \%)$ during the full tidal cycle, In the other stations, the variation of salinity due to the landward and seaward moving water mass is clearly visualized. During the floating measurements, it was the intention to perform the measurements, as much as possible, in the same water mass. 
Fig. 1 Locations of field measurements in the Ems Estuary
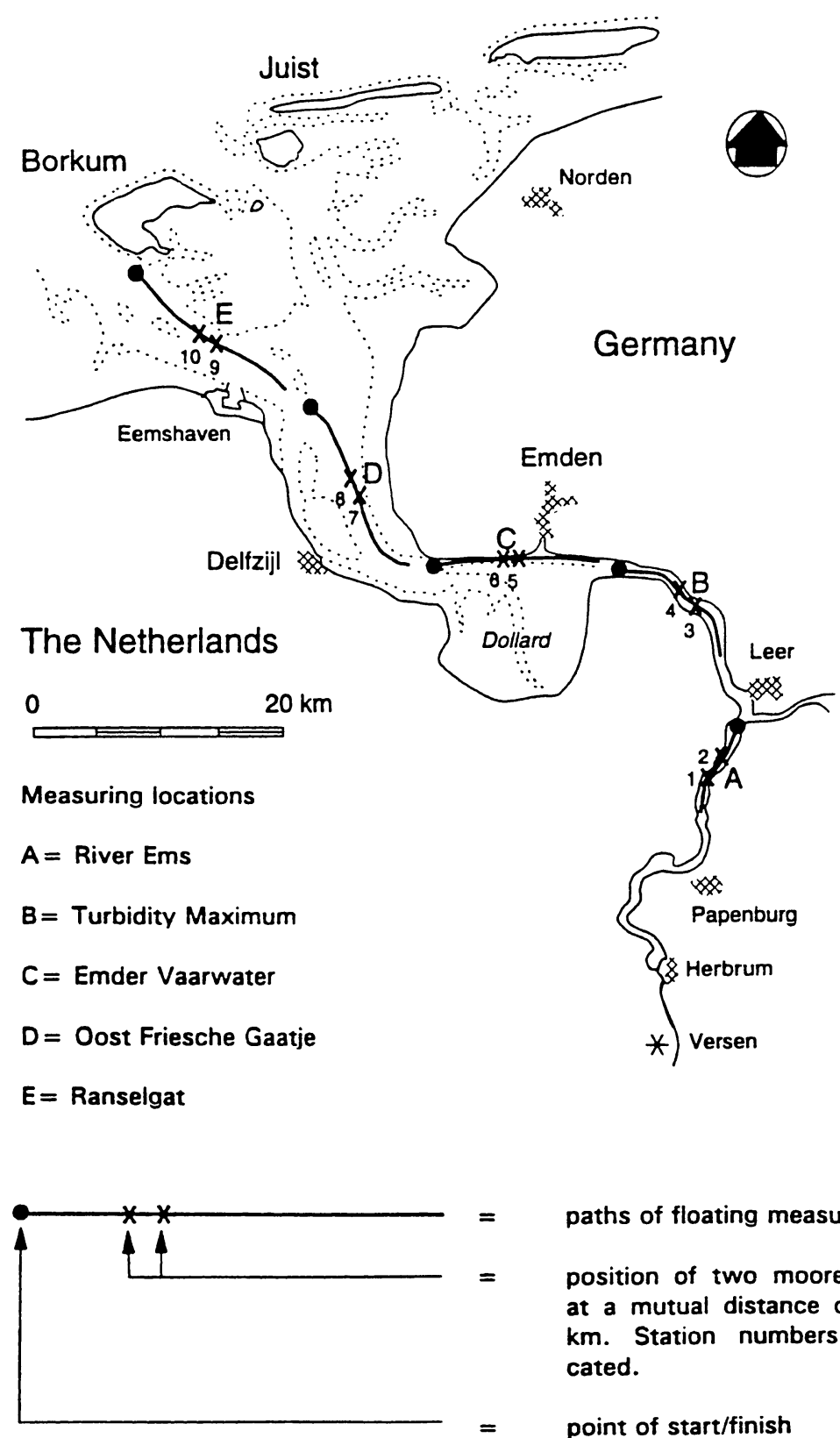

paths of floating measurements

position of two moored stations at a mutual distance of about 1 $\mathrm{km}$. Station numbers are indicated.

point of start/finish
The salinities are presented in Fig. 2b. The figure shows that, while drifting during the tidal cycle, the salinities remain nearly constant. Only in the Emder Vaarwater and the turbidity maximum areas did some deviations occur. At all the stations, the salinity was vertically almost homogeneously distributed during the full tidal cycle. Only measurements in the Emder Vaarwater showed a slight stratification. During the measurements in the turbidity maximum, a stratified area was observed in the bottom layers around high water slack (HWS). This was attributed to the appearance of a dense fluid mud layer.

The suspended sediment concentration varied strongly both in time and in depth. Figure 3 shows the contoured distributions for the five locations during a full tidal cycle.
In fact, this figure is a summarized visualization of the erosion/sedimentation cycles at various locations in the Ems Estuary. The enormous differences in suspended sediment concentrations between the various locations are largely determined by the differences in the properties of the bottom and especially the top layer of the bed. The figures clearly illustrate the resuspension of the fine-grained sediment at a short period of time after LWS owing to the strongly increasing flood currents. Thereafter, the vertical dispersion of the eroded sediment can be observed, followed by sedimentation of the suspended sediment. During this sedimentation process, the sediment remains vertically fairly uniformly distributed in the case of low 
Fig. 2 Variation of the salinity during a tidal cycle at the five measuring locations along the Ems Estuary. a moored stations b floating measurments
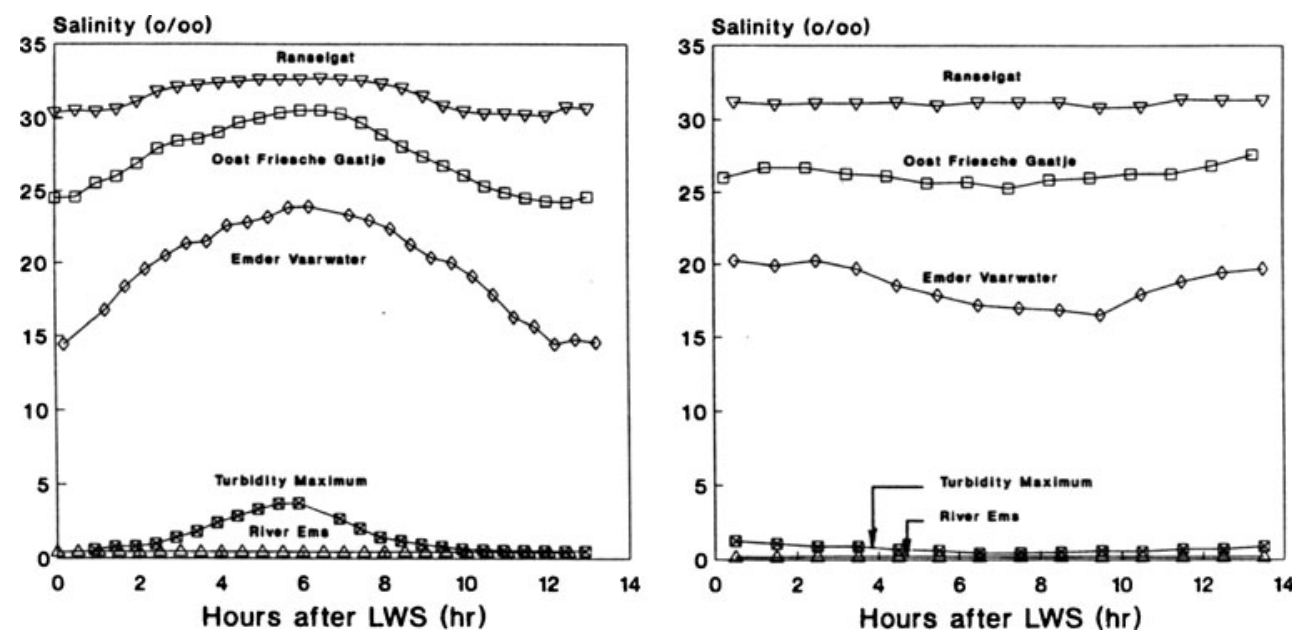

suspended sediment concentrations and is more stratified in the case of higher suspended sediment concentrations (cf. Oost Friesche Gaatje vs. Emder Vaarwater and River Ems in Fig. 3). This may be attributed to relatively high settling velocities owing to the relatively rapid formation of large aggregates as a result of the relatively high suspended sediment concentration. In the turbidity maximum location, an extremely stratified situation occurred because of the appearance of a fluid mud layer (Fig. 3d).

From the VIS video recordings, the sizes and settling velocities of "characteristic flocs" were analyzed. "Characteristic flocs" means that these flocs were observed on the video recordings as representative for the present situation. In fact, they form the highest class of abundantly appearing flocs, the so-called macroflocs. For the Ranselgat, Fig. 4a shows that, during high flow velocities, the settling velocities increased to about $4 \mathrm{~mm} / \mathrm{s}$, both during flood and ebb. The corresponding floc sizes were 400-600 $\mu \mathrm{m}$. In the Oost Friesche Gaatje, the results are quite similar (Fig. 4b), although the suspended sediment concentrations are considerably higher than in the Ranselgat (20-50, respectively, 50$200 \mathrm{mg} / \mathrm{l}$ during high flow velocities). In the turbidity maximum area, the suspended sediment concentration was much higher (several thousands of milligrams per liter). However, the settling velocities at periods of high flow currents were somewhat smaller $\left(w_{\mathrm{s} \max } \sim 3 \mathrm{~mm} / \mathrm{s}\right)$. Also, in the River Ems location, the suspended sediment concentration was fairly high $(500-1,500 \mathrm{mg} / \mathrm{l})$ and the settling velocities of the macroflocs showed comparable results: an increase of the settling velocities up to several millimeters per second shortly after maximum flow velocity.

\section{Erosion/sedimentation cycles}

The aforementioned erosion/sedimentation cycles are characteristic features of the behavior of fine-grained sediment during a tidal cycle. During periods of decelerating currents, significant decreases occur in the suspended sediment concentration over a relative short period of time $(<1 \mathrm{~h})$.

An example is given in Fig. 5 for the Emder Vaarwater. The data are from the floating measurements. The depthaveraged current velocities show an increase up to $u_{\text {max }} \approx 1.20 \mathrm{~m} / \mathrm{s}$. The curves of the depth-averaged suspended sediment concentration show a deep descent from the point where the depth-averaged current velocities start to decrease. At some locations, especially in the vicinity of the turbidity maximum, the depth-averaged suspended sediment concentrations are significantly influenced by layers of high turbidity in the near vicinity of the bed. Therefore, depth-averaged concentrations are also presented for $z \geq 1.00 \mathrm{~m}$ and $z \geq 2.00 \mathrm{~m}$, where $z$ is the height above the bed.

Analysis of these erosion/sedimentation cycles during the depositional phase showed that effective settling velocities occur of several millimeters per second, even in the case of relatively low suspended sediment concentration van Leussen (1996a). The real settling velocities must be in the order of $2-7 \mathrm{~mm} / \mathrm{s}$.

The characteristics of these erosion/sedimentation cycles can be summarized as:

- Erosion/sedimentation cycles are characteristic features of fine-grained sediment dynamics during a tidal cycle.

- An abundance of large flocs is observed shortly after maximum current velocity.

- Significant decrease in the suspended sediment concentration occurs during periods of decelerating currents ("rapid settling").

- Only large aggregates with high settling velocities can explain this phenomenon.

- These settling velocities are in the order of $2-7 \mathrm{~mm} / \mathrm{s}$ and are in the same range as those of the macroflocs. 
Fig. 3 Contoured distributions of suspended fine-grained sediment concentration (grams per liter) for five locations in the Ems Estuary during a full tidal cycle (floating measurements)
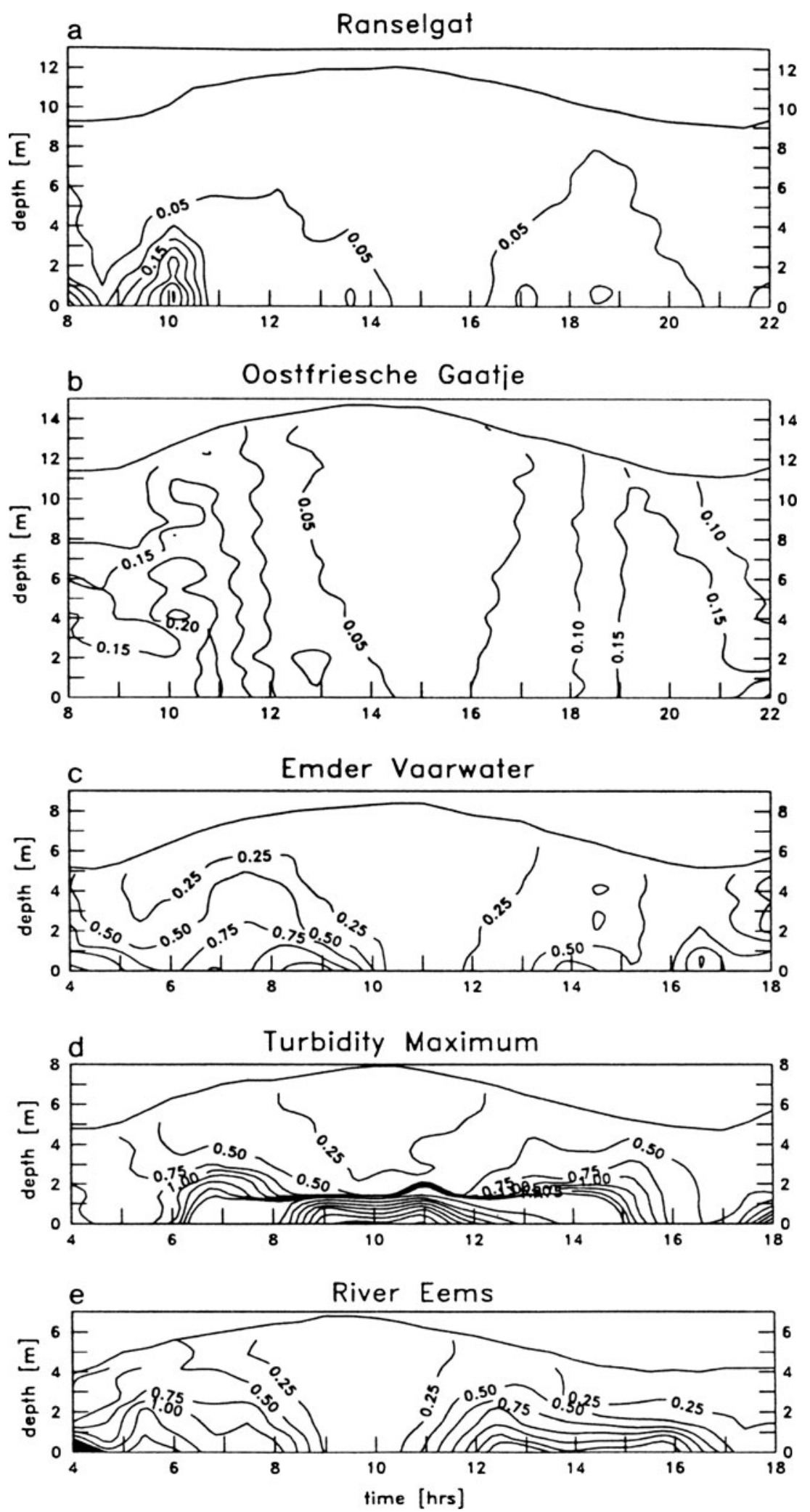
a)

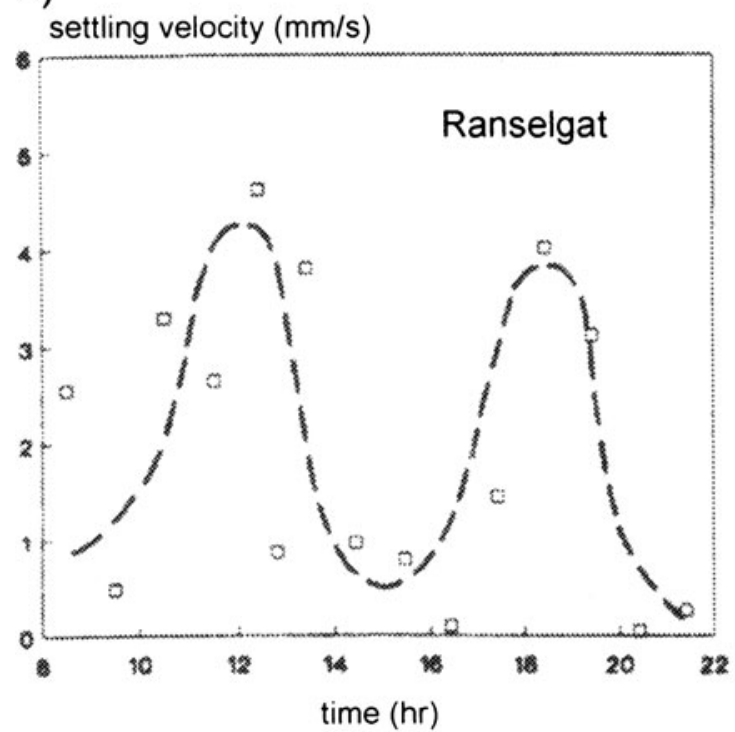

c)

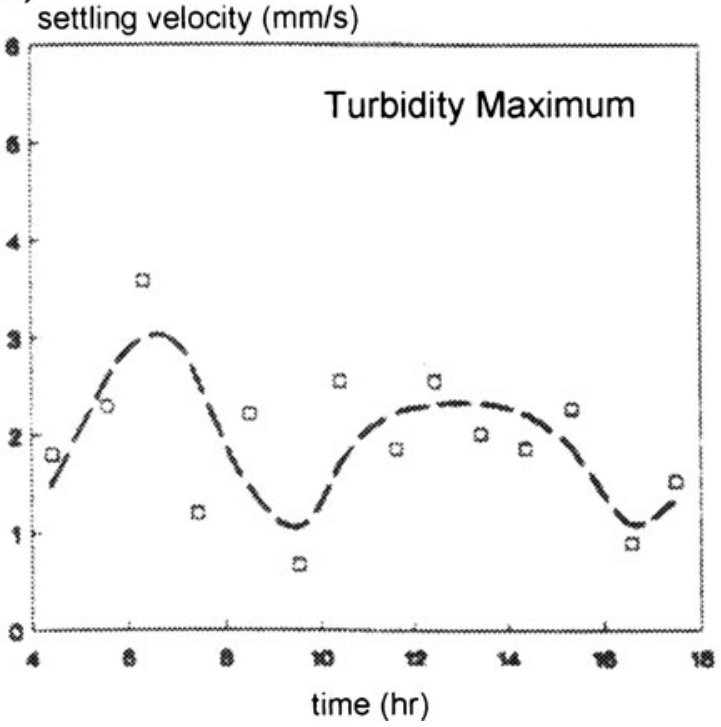

b)

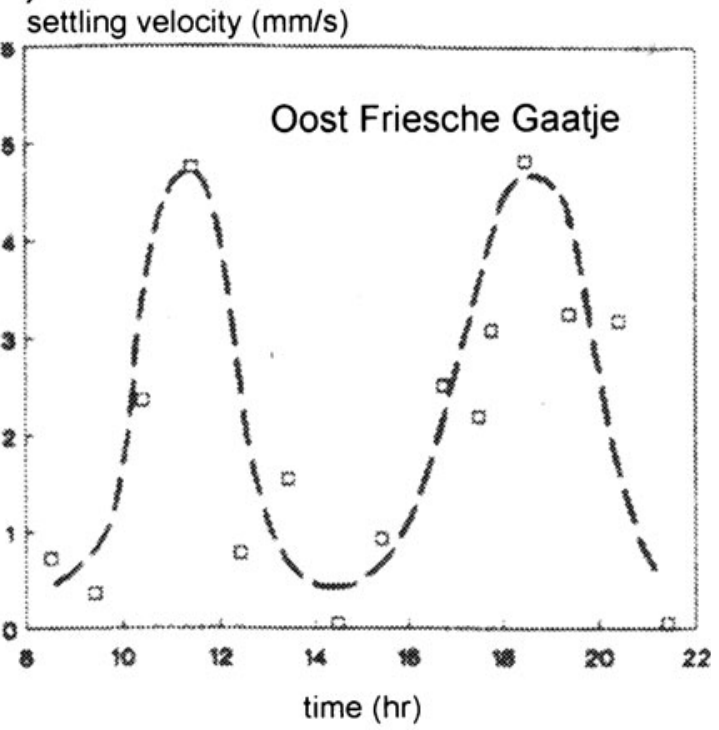

d)

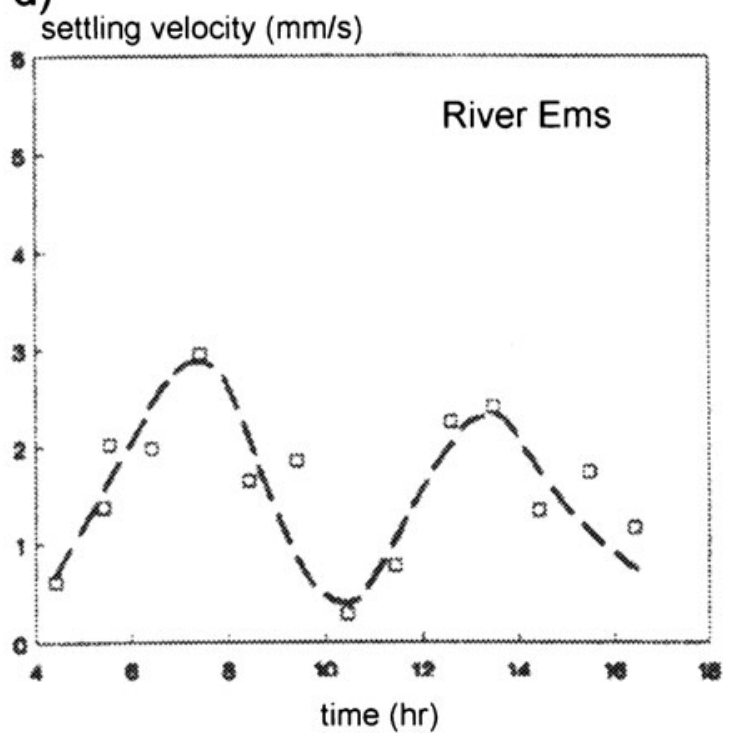

Fig. 4 Results of VIS measurements in the Ems Estuary. Settling velocities of macroflocs. a Ranselgat. b Oost Friesche gaatje. c Turbidity maximum. d River Ems

To obtain more insight into the role of the large macroflocs, an analysis has been made of the contribution of the various fractions of the suspended sediment to the vertical flux of the suspended sediment. Floc size distributions have been derived from the video recordings for all suspended flocs with a diameter above $50 \mu \mathrm{m}$ and divided up into a number of size classes. For each size class, the number of flocs was determined, and an assessment has been made of their contribution to the vertical flux (see Fig. 11 in van Leussen and Cornelisse 1993b). It became clear that the largest number of suspended particles belongs to the lower size classes, but that the vertical flux is governed by the large aggregates due to their much larger settling velocities. It was shown that the settling velocities of the macroflocs, derived from the video recordings, showed a good correspondence with the settling velocities, derived from the changing concentration profiles (see Fig. 10 in van Leussen and Cornelisse 1993b). So, it became clear that the large macroflocs affect the mean settling velocity significantly and are responsible for the phenomenon of "rapid settling". 

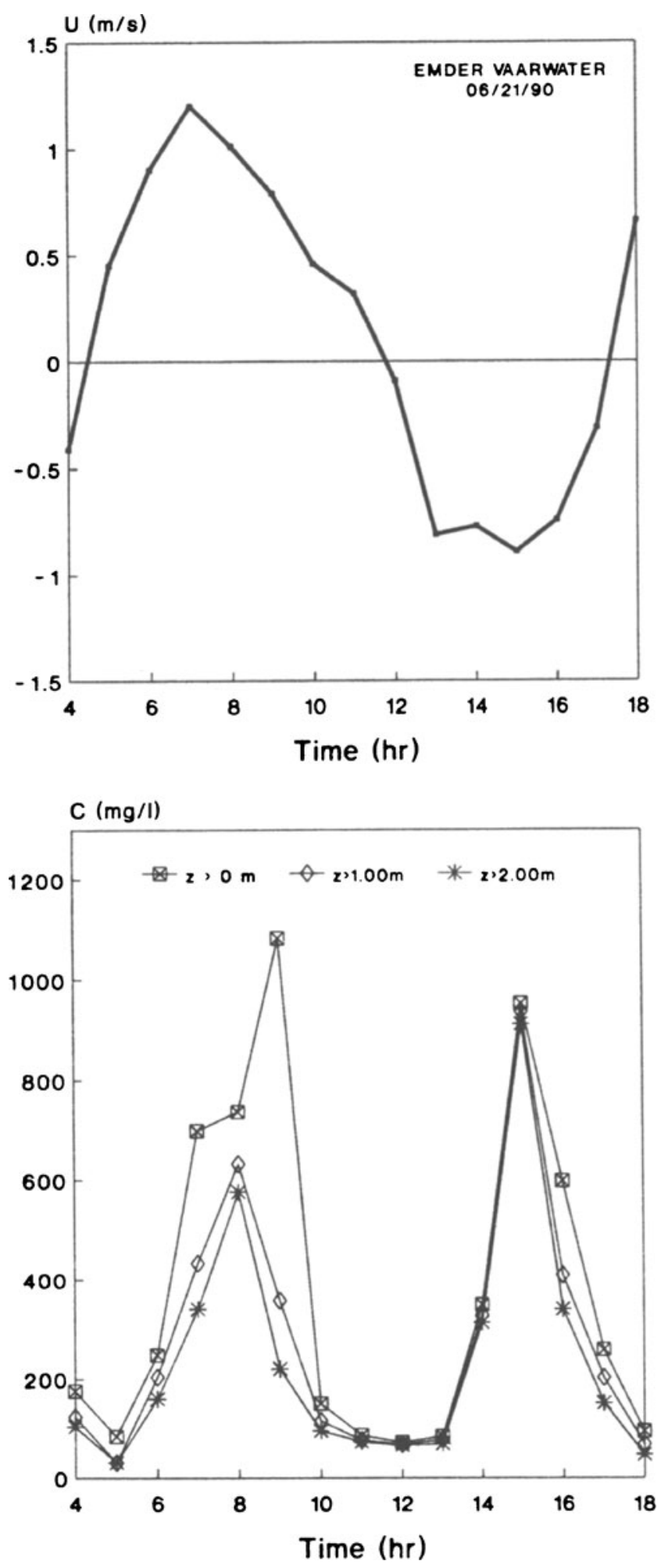

Fig. 5 Depth-averaged current velocities and suspended finegrained sediment concentrations, averaged over the total depth $H$, over $1.00 \mathrm{~m}<z<H$, and over $2.00 \mathrm{~m}<z<H$. Results for the location Emder Vaarwater

\section{Research to determine the longitudinal variation of the "flocculation ability" of the suspended fine-grained sediment}

We learned that the ultimate size of the suspended flocs is the combined effect of floc growth-limiting process and floc growth-stimulating factors such as cohesivity, turbulence, suspended sediment concentration, and the size distribution of the resuspended sediment particles. Most of these factors vary significantly along the estuary. Whereas the suspended sediment concentration and the turbulence affect the floc growth principally through the increased number of particle collisions, physico-chemical and biological parameters affect the floc growth principally through their effect on the efficiency of these collisions (Van Leussen 1994; Winterwerp and Van Kesteren 2004).

To quantify this efficiency, the concept of flocculation ability proved to be useful (Van Leussen 1999). It is determined by laboratory experiments in a 1.50-m settling tube, diameter $0.14 \mathrm{~m}$, all starting at the same homogeneously distributed fine-grained sediment concentration of $1,000 \mathrm{mg} / \mathrm{l}$. This choice has been made to compare the potential of floc formation with exclusion of differences in turbulence and suspended sediment concentration. The "flocculation ability" is then the resulting settling velocity. In fact, it is a measure for the floc growth rate and the resulting settling velocities under unambiguously defined circumstances (the same number of particle collisions per unit of time).

It would be interesting to know more about the variation of this flocculation ability along the estuarine axis of the estuary. Therefore, the abovementioned laboratory settling experiments were conducted on water and suspended sediment samples from 12 locations along the estuarine axis. They were taken at $2.80 \mathrm{~m}$ below the water surface around periods of maximum current velocities when the largest amounts of sediment were in suspension. These settling experiments showed that, although the physical circumstances (suspended sediment concentration and turbulence level) were the same, the resulting settling velocities, and thus the flocculation ability, varied over almost an order of magnitude over the length of the estuary (see Fig. 6). Because the water mass and the turbidity maximum are shifting forward and backward under influence of the varying river discharge, the longitudinal variation of the various parameters are presented as a function of the salinity. To obtain sufficient details of the longitudinal variations in the freshwater part of the estuary, the values of the various parameters in that region are presented as a function of the longitudinal distance.

The surface charge developed at the solid-solution interface is a parameter which reflects the nature of the surface and may be of major importance in the flocculation of suspended fine-sediment particles. Both in studies on salt 


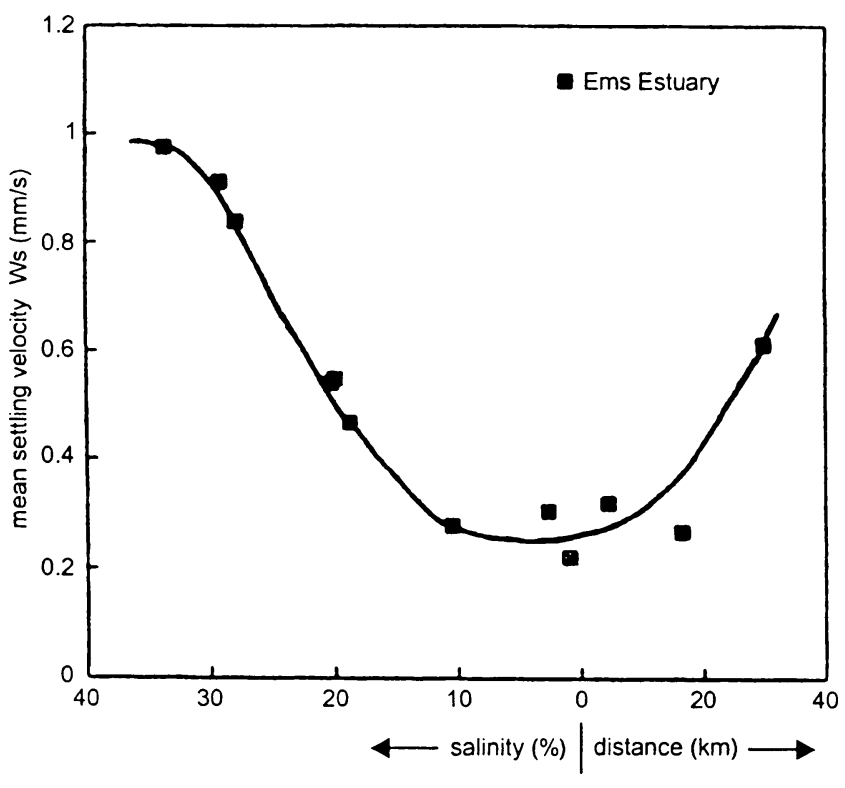

Fig. 6 Longitudinal distribution of the "flocculation ability" of the suspended sediment in the Ems Estuary, represented by mean settling velocities from laboratory settling column experiments for $C_{\mathrm{o}}=1,000 \mathrm{mg} / \mathrm{l}$

flocculation and in the case of bridging particles by polymers, the surface charge is an important parameter in flocculation studies (see overview in Van Leussen 1994). The zeta potential is a good representation of the surface charge, but generally, it is more convenient to measure the electrophoretic mobility (EM). From electrophoretic measurements in several estuaries with a wide variety of sediment particles, it was shown by Neihof and Loeb (1972, 1974), Gibbs (1977), Hunter (1980), and Hunter and Liss (1982) that the surface charge is not determined by the properties of the sediment particles but by coatings of natural organic matter on the particle surfaces.

For the samples from these laboratory experiments, as well as from the field cruise, the electrophoretic mobilities were determined by a Malvern Zeta-sizer II. Both series are presented in Fig. 7. The figure confirms the negative charge of the fine-grained particles, entering the Ems Estuary through the river boundary. During estuarine mixing in the fresh water part of the estuary, a further decrease of EM was observed, reaching a minimum value of about $-1.2 .10^{-8} \mathrm{~m}^{2} \mathrm{~V}^{-1} \mathrm{~s}^{-1}$ in the low-salinity region. In the seaward direction, the EM increased up to about $-0.3 \times 10^{-8} \mathrm{~m}^{2} \mathrm{~V}^{-1} \mathrm{~s}^{-1}$ at the seaward boundary. Such a longitudinal distribution corresponds fairly well with results in other estuaries, such as, for example, the Gironde and Loire estuaries (Martin et al. 1986), the Raša River Estuary (Sondy and Pravdic 2002), and the Changjiang Estuary (Liu 2006; Liu and Qui-zhen 2007). It may be expected that these values are governed by (organic) coatings on the surfaces of the particles, together with the amount and valency of dissolved cations in the water.
Scanning electron microscopy (SEM) was applied to obtain information on the microstructure of the sediment. From the SEM photographs, it could be derived that the fragile macroflocs were destroyed through the sampling procedure. So, these photographs give more an impression of the underlying "building blocks" of the macroflocs, particularly the so-called microflocs. The SEM photographs showed significant variations along the estuarine axis. At the river boundary, several loosely bounded flocs were observed with dimensions up to $150 \mu \mathrm{m}$. Within such flocs, a large number of diatom skeletons were detected. Some details are given in Fig. 8a. However, also more compact microflocs were observed with dimensions of about $40 \mu \mathrm{m}$ and consisting of a variety of organic debris. In the lowsalinity region, a large number of flocs in the range of 5 to $30 \mu \mathrm{m}$ was observed (Fig. 8b). The flocs are primarily of biological origin. A characteristic photograph from the Friesche Gaatje/Emder Vaarwater is presented in Fig. 8c. It shows fragments of flocs over a wide size range: from very small particles up to flocs of about $100 \mu \mathrm{m}$. In the Ranselgat area, a large number of flocs were observed in the range of 50 to $100 \mu \mathrm{m}$ (Fig. 8d) composed of parts of diatoms, remainders of plants, quartz particles, and organic debris. Also, fecal pellets were commonly observed in this area.

The SEM photographs showed that the largest components were found in the seaward area (Ranselgat: both aggregates and fecal pellets). The smallest sizes were found in the low-salinity area (turbidity maximum area). Additionally, the microphotographs indicated the highest biological activity at both ends of the estuary (seaward

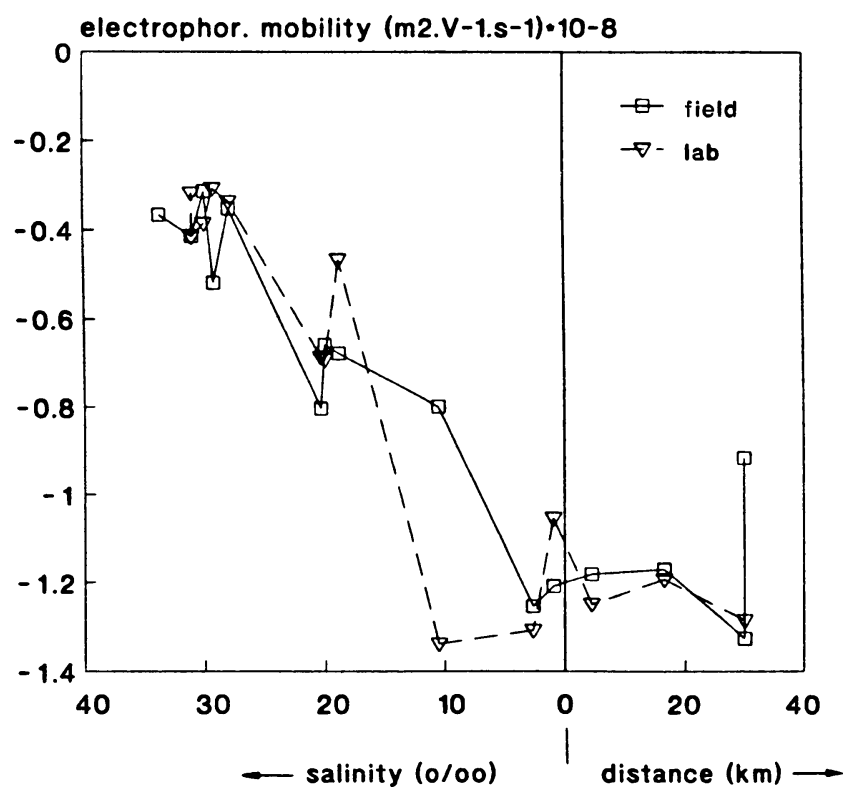

Fig. 7 Longitudinal distribution of the electrophoretic mobility, both for samples from the field and samples taken during the laboratory settling column experiments 
Fig. 8 Examples of SEM microphotographs of particles and flocs from a River Ems, $\mathbf{b}$ low-salinity area (turbidity maximum), c Friesche Gaatje/ Emder Vaarwater, $\mathbf{d}$ seaward area of the Ems Estuary (Ranselgat). The bar lengths, representing the indicated lengths, are depicted at the bottom of the photographs

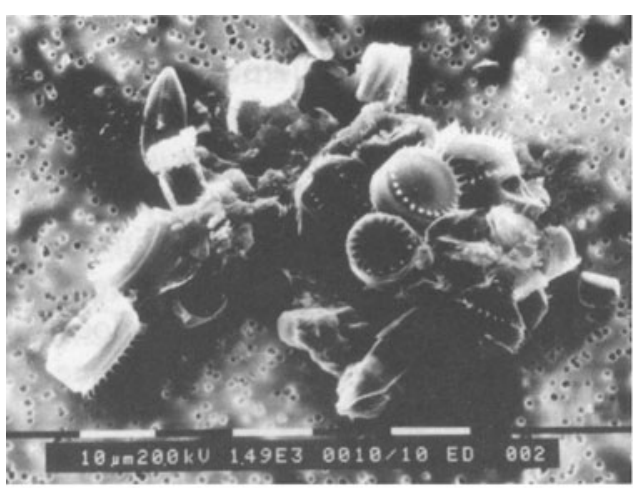

a)

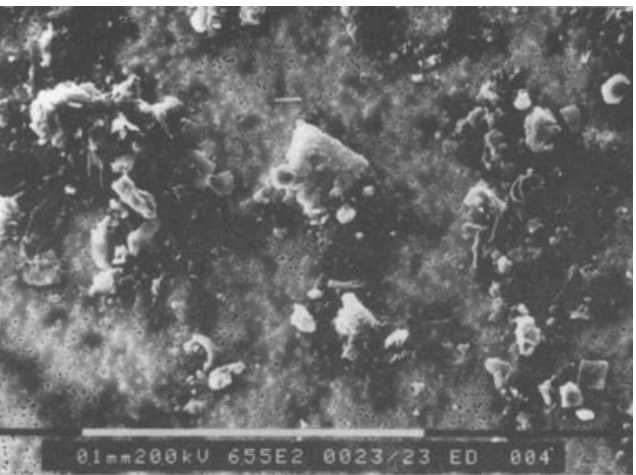

b)

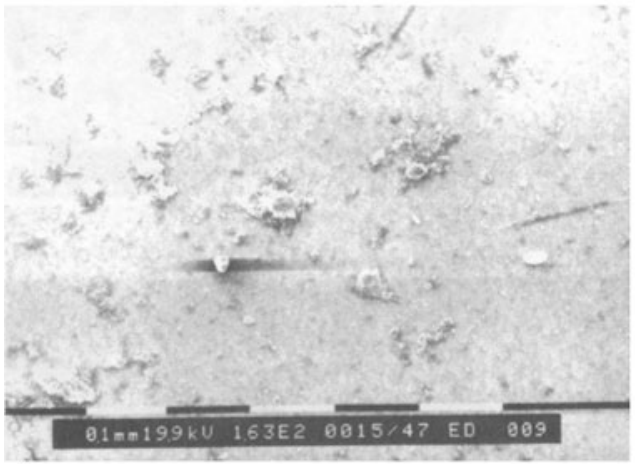

c)

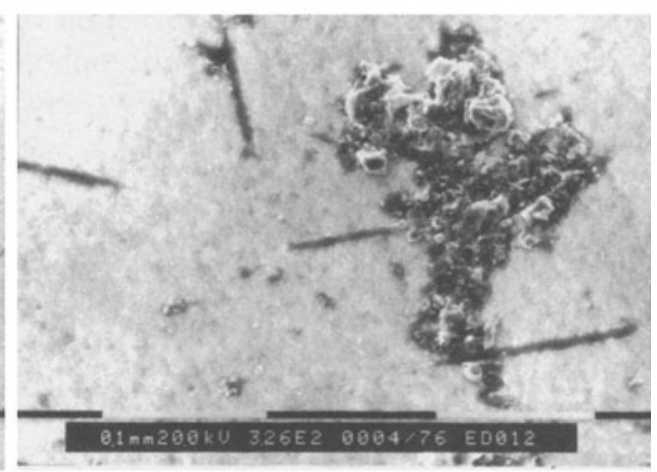

d) boundary and freshwater region). So, it may be concluded that the variation of this material, which forms the "building blocks" of the macroflocs, may contribute significantly to the "flocculation ability" of the suspended fine-grained sediment, both due to the variation of sizes, surface charge as biological activity. So, it may be expected that they ultimately contribute essentially to the longitudinal distribution of sizes and settling velocities of the macroflocs.

During the field cruise, measurements with the RWS field settling tube (van Leussen 1996b) have also been carried out. In Fig. 9, the results are summarized, assuming the power law relation $w_{\mathrm{s}}=K \times C^{m}$ between the settling velocity $w_{\mathrm{s}}$ and the suspended sediment concentration $C$. It is well known that these values of $w_{\mathrm{s}}$ are not representative for those of the macroflocs because, owing to their fragile structure, they are partially or totally destroyed during sampling (van Leussen and Cornelisse 1993b; Dyer et al. 1996; Eisma et al. 1997; Manning and Dyer 2002; Mantovanelli and Ridd 2006; Maa and Kwon 2007). Nevertheless, it illustrates that, within one estuary, the $w_{\mathrm{s}}-C$ relation can vary enormously, which must be attributed to the varying "flocculation ability" along the estuarine axis. Such differences also appear when a comparison is made between such settling velocities from different estuaries. It may be hypothesized that the wide variety of $w_{\mathrm{s}}-C$ relations from the various estuaries in the world has this background.

\section{Longitudinal variations of the fine-grained sediment transports}

Although the fine-grained sediment particles are participating in an extremely dynamic process, with strong variations both in time and space, the ultimate transports are of utmost importance due to problems of siltation in harbors and navigation channels and the transport of various substances, which adsorb to the fine-sediment particles, such as micropollutants, nutrients, and radionuclides. It will be shown how the long-term transports of fine-grained sediment are coupled to the strongly variable short-term (vertical) transports and how the phenomena, discussed in the previous sections, are at the basis of these variations of the fine-grained transport along the estuarine axis.

Under influence of the tide, the fine-grained sediment particles in estuaries are transported forward and backward, participating in a step-wise transport with deposition and resuspension. Generally, this step-wise transport is not symmetrical so that each tidal cycle results in a net transport in the seaward or landward direction. A number of phase lags are responsible for these asymmetric transports. Generally, they have their background in differences in the horizontal and vertical movements between the water and the suspended sediment, where critical values for sedimentation and erosion and time scales for vertical mixing play an essential role. The distortion of the flood and ebb tides and their resulting asymmetric forms result 
Fig. 9 Relationship between median settling velocities and suspended sediment concentration from field settling tube measurements (RWS field settling tube) at five locations in the Ems Estuary

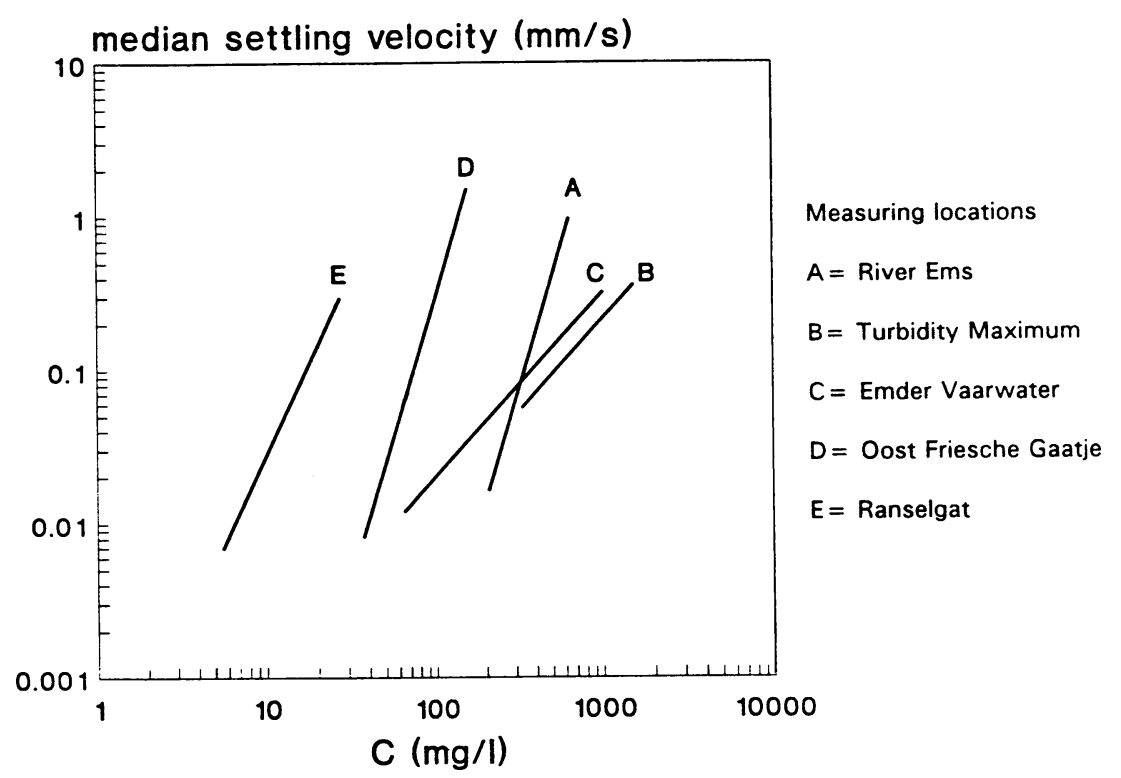

from the interaction between the tidal currents and the estuarine topography. Both the estuarine geometry and the friction characteristics are of importance. Also, gravitational circulation can contribute significantly to the tidally averaged transports, whereas near-bottom suspension layers can affect the transports through damping of the turbulence. The relative importance of these mechanisms in a number of estuaries has been discussed by many authors (Postma 1967; Van Leussen 1991; Le Hir et al. 2001; Vinzon and Mehta 2001; Dyer et al. 2002a; Bass et al. 2005; Nakagawa and Yoshida 2008).

In section 4, it was outlined that erosion/sedimentation cycles are the characteristic features of fine-grained sediment transport under tidal conditions. Together with the often very strong tidal currents, large horizontal transports result in both the flood and ebb direction. Generally, the resulting transport over one tidal cycle is relatively small in comparison with these large forward and backward sediment movements. Nevertheless, we remain most interested in the tidally averaged transports due to their contribution to the transports over longer periods of time.

For each measuring location, fine-grained sediment fluxes during a tidal cycle and their distribution of the water column are presented in Fig. 10. In this figure, the vertical scale (water depth) is the same for each location; the horizontal scales (sediment fluxes) are different, owing to the wide range of suspended sediment concentrations along the estuary. Each series was started around LWS. The sediment fluxes at the most seaward station (Ranselgat location) illustrate the rapid increase of the transports in the lower part of the water column during a relatively short period of increasing flood currents after LWS. Thereafter, the horizontal sediment fluxes are vertically fairly homogeneously distributed as a result of turbulent mixing. The profiles of the fluxes in the Oost Friesche Gaatje show a similar behavior, although the fluxes in the Emder Vaarwater and River Ems location are more stratified, probably due to much higher suspended sediment concentrations, their effects on the settling velocities and the vertical mixing through damping of the turbulence, and somewhat less vertical mixing owing to the decrease of the maximum tidal currents. In the turbidity maximum, a large contribution to the sediment fluxes exists near the bottom, when the fluid mud layer appears (Fig. 10d).

The resulting vertically averaged transports show a strong increase of the longitudinal fine-grained sediment transport after LWS, when the flood currents rapidly increase over a relatively short period of time. Thereafter, they decrease significantly during the period of decelerating flood currents as a result of the sedimentation process, including "rapid settling". Figure 11 shows the tidally averaged transports of fine-grained sediment over $1 \mathrm{~m}$ width for each of the measuring stations. Also, the total transports in ebb and flood direction are presented. The figure shows that the resulting transport is a relatively small difference between two large values. Large forward and backward transports occur especially in the area of the turbidity maximum per meter width around 70 tonnes dry material in both directions. In the locations River Ems and turbidity maximum, the mean transports are sometimes in the landward and sometimes in the seaward direction. At the seaward part of the estuary (Ranselgat and Oost Friesche Gaatje), the tidally averaged transports are in the landward direction. In the Emder Vaarwater, both stations show a significant tidally averaged transport in the seaward direction. The higher sediment transports in the ebb phase are caused by a less stratified situation in this phase of the tide (cf. Fig. 3c), an asymmetric curve of the currents 


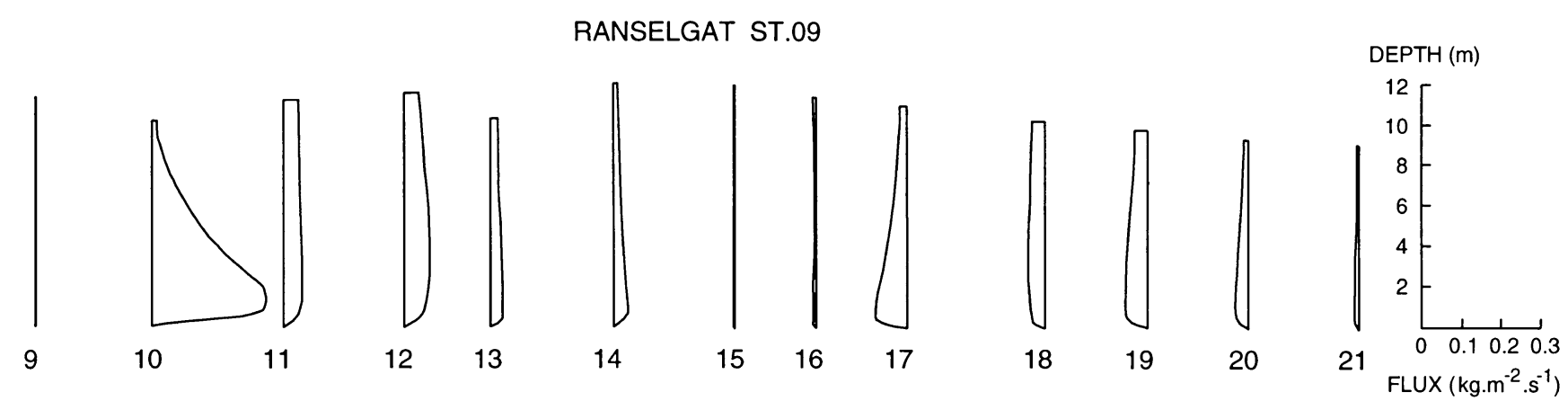

OOST FRIESCHE GAATJE ST.07
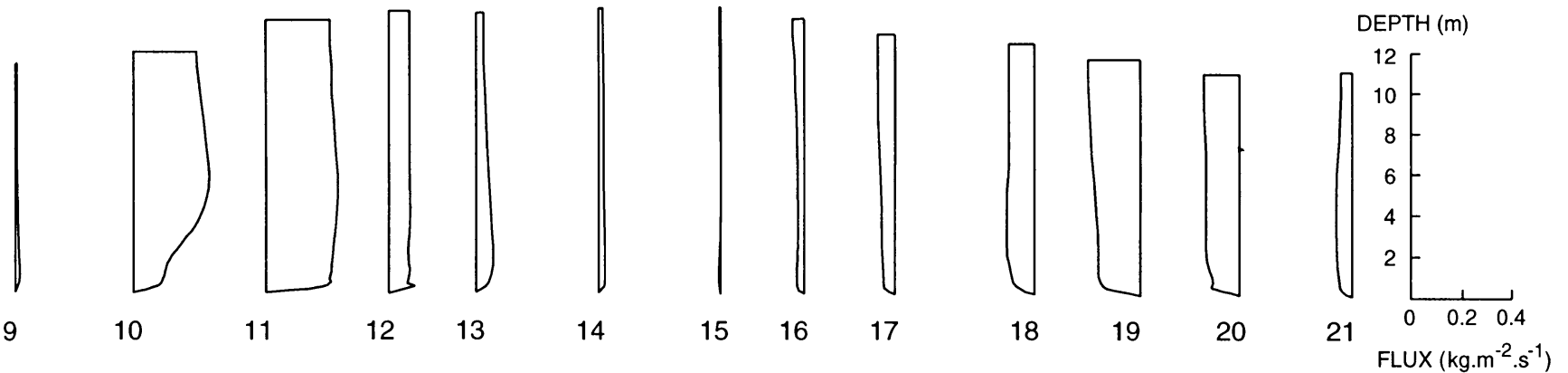

EMDER VAARWATER ST.05
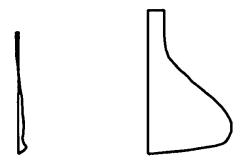

6

5
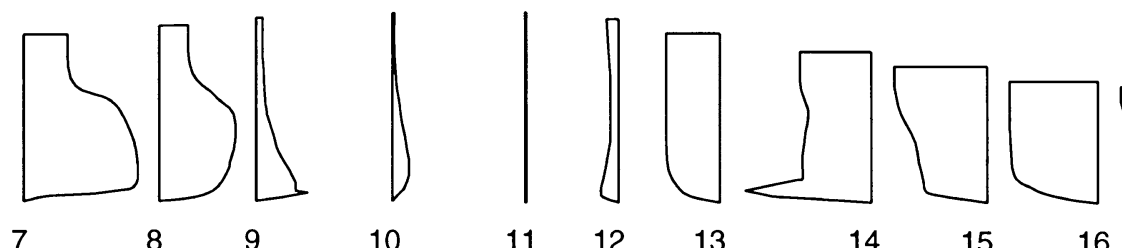

13

15
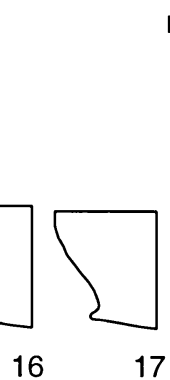

$\operatorname{DEPTH}(m)$
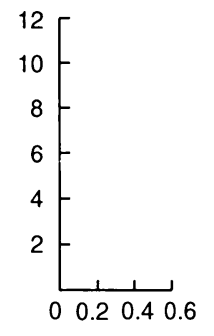

FLUX $\left(\mathrm{kg} \cdot \mathrm{m}^{-2} \cdot \mathrm{s}^{-1}\right)$

TURBIDITY MAXIMUM ST.03

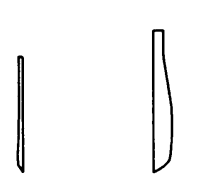

5
6

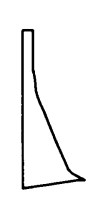

7

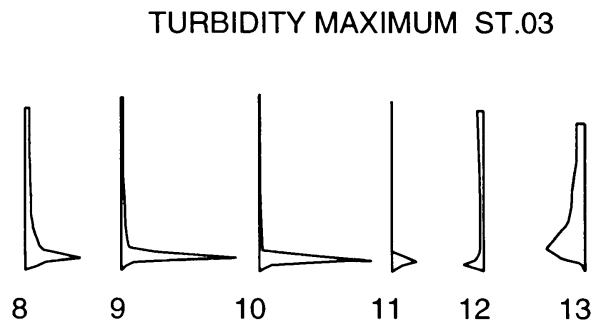

RIVER EMS ST.01
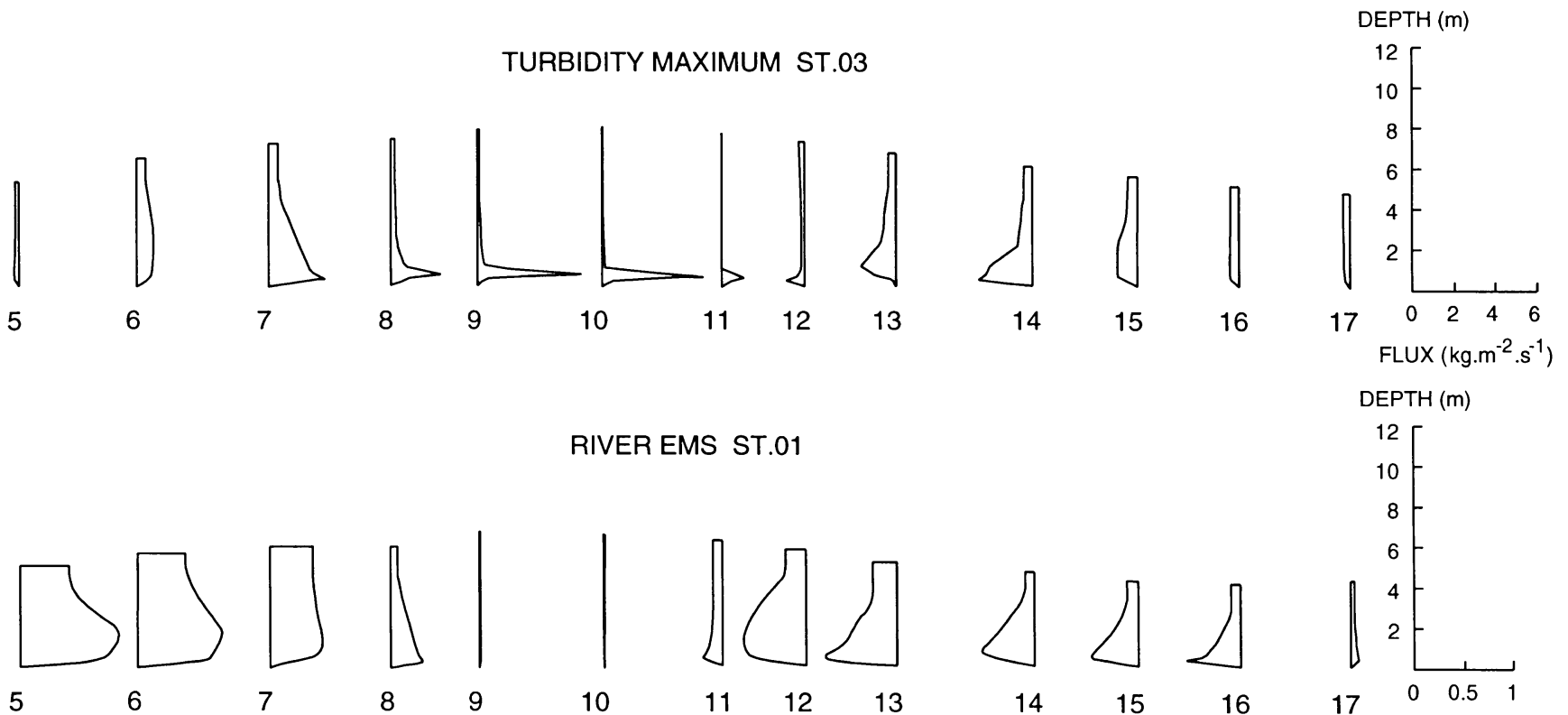

Fig. 10 Suspended fine-grained sediment flux profiles in the Ems Estuary during a full tidal cycle for the locations Ranselgat, Oost Friesche Gaatje, Emder Vaarwater, turbidity maximum, and River Ems 
Fig. 11 Flood-, ebb- and tidally averaged transports of finegrained sediments per unit width at five locations in the Ems Estuary: Ranselgat (Rsg), Oost Friesche Gaatje $(O F G)$, Emder Vaarwater $(E V w)$, turbidity maximum $(T b M)$, and River Ems (R.Ems)

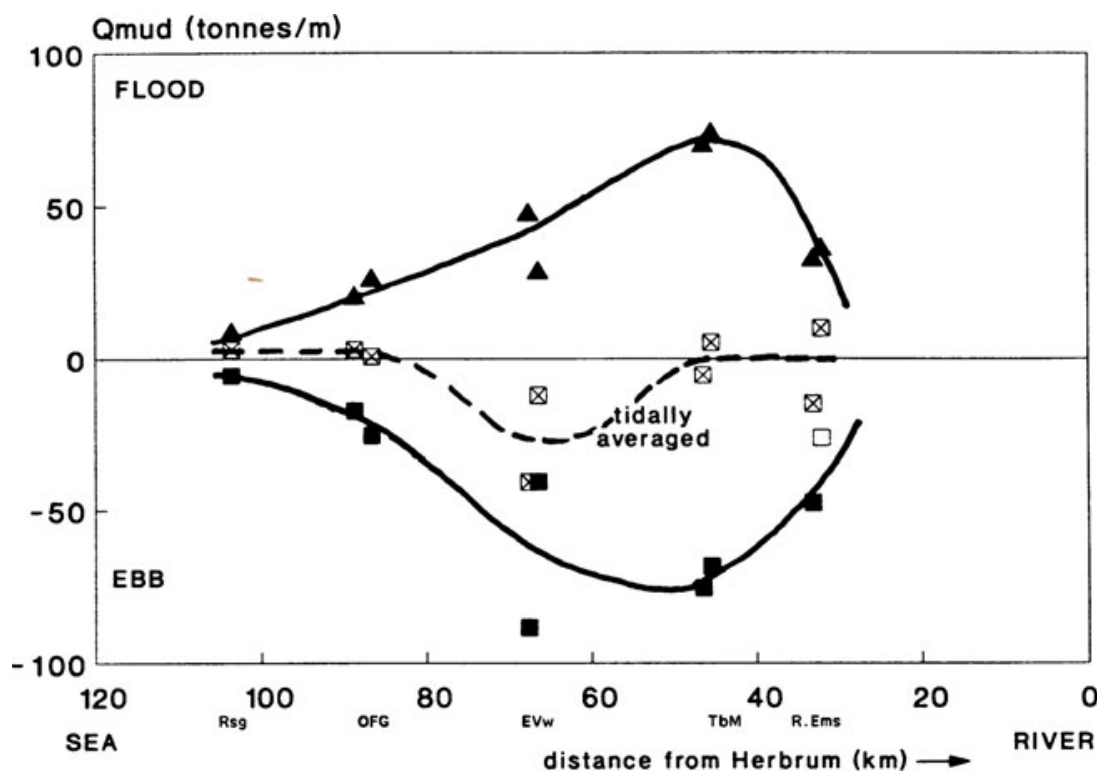

during the tidal cycle (cf. Fig. 5), and higher suspended sediment concentrations in the upper part of the water column. The high suspended sediment concentrations in the second half of the ebb period could be caused by the arrival of fine sediment from the turbidity maximum area.

Furthermore, it is known that the transports can also differ considerably over a cross-section. The topography is complex, and a complicated flow system arises from the interaction of the tide and the river discharge with topography. Additionally, the erosion properties of the bed vary over the cross-section, where muddy deposits are mainly found at the edges of certain tidal flats, bordering the deeper channels. This is discussed in more detail in Van Leussen (1991) and Andersen et al. (2006), where it is concluded that the exchange of fine-grained material between the tidal flats and the deeper channels is essential in the total fine-sediment transport. It is the impression that a slide of the muddy channel banks also contributed to higher suspended sediment concentrations in the second half of the ebb period. It stresses the complicated threedimensional dynamics of the fine-grained sediment transport. Such findings were also presented by Lumborg and Pejrup (2006), who investigated the Lister Dyb tidal area in the Danish part of the Wadden Sea and used a numerical simulation model to quantify the net sediment transport of cohesive sediment through a control cross-section in a tidal inlet. They showed that the net transports during 1 day can vary significantly over longer periods of time. They stressed the need for sediment budget studies over longer periods of time by combined field measurements (shortterm and long-term) and numerical modeling. Such models should include the exchanges between tidal flats and the deeper channels, and attention must be given to different conditions of onshore wave activity and varying river discharges. When the river discharge increases, the turbidity maximum shifts in the direction of the Emder Vaarwater. It should be noticed that, often, the turbidity maximum is located in the Emder Vaarwater, but, because of the very low river discharge $\left(Q_{\mathrm{f}} \approx 10-25 \mathrm{~m}^{3} / \mathrm{s}\right)$, this area was now located in a more landward position.

Notwithstanding this complex three-dimensional character of the total fine-grained sediment transport in estuaries and its dynamic behavior under varying boundary conditions, the analysis of the fine-grained sediment transport in the five measuring locations showed that time lags between current velocity and suspended sediment concentration contribute significantly to the tidally averaged transports. The vertical transports - the local erosion/sedimentation cycles - are responsible for these time lags. In fact, they demonstrate that the short-term vertical transports are the building blocks for the ultimate long-term horizontal transports.

Because the macroflocs play a key role in this process, in the next section, we will look for the longitudinal distribution of the sizes and settling properties of the macroflocs.

\section{The longitudinal variation of macroflocs in the Ems Estuary}

VIS measurements at the five locations in the Ems Estuary showed that, at periods of high current velocities, estuarine macroflocs appeared with sizes in the range of 200 to $600 \mu \mathrm{m}$ and settling velocities of 2 to $5 \mathrm{~mm} / \mathrm{s}$. Exceptionally, macroflocs with dimensions larger than $500 \mu \mathrm{m}$ were observed with settling velocities up to $8 \mathrm{~mm} / \mathrm{s}$. Similar phenomena were observed in other estuaries, for example, in the Tamar Estuary (Fennessy et al. (1994); Dyer et al. 
2002b; Manning and Bass 2006), the Changjiang Estuary (Zhong Shi et al. 2003), and the Lower Scheldt Estuary (Winterwerp et al. 2006; Manning et al. 2007).

The question arises as to how the sizes and settling properties of such macroflocs vary along the estuary. The longitudinal distribution of the sizes of the macroflocs in the Ems Estuary is summarized in Fig. 12. Each point indicates the average of the sizes of the macroflocs during flood and ebb. All measurements were carried out at $2.80 \mathrm{~m}$ below the water surface. The salinity and suspended sediment concentration, indicated in this figure, were also measured at this level.

The figure shows a distinct turbidity maximum in the area of low salinity. It is remarkable how the largest flocs appear at the seaward boundary where the lowest suspended sediment concentrations were observed. This stresses the aforementioned statement that, also at low suspended sediment concentrations, large macroflocs can be formed. From the river boundary, the sizes of the macroflocs seem to increase to the point of maximum salt intrusion c.q. the turbidity maximum. There, the floc sizes decrease, and after it, they were increasing up to the sea boundary.

The question arises as to what factors determine these sizes and corresponding settling velocities of the macroflocs. In fact, the flocs are in a continuous process of floc growth and floc breakup. In this process, the turbulence in the water is an important factor. It stimulates both the floc growth (number of particle collisions) and the floc breakup (turbulent shear). Results from both laboratory experiments and field measurements have shown that, due to the very fragile nature of the aggregates, the final size distribution of the flocs is governed by the disruptive properties of the turbulence field.
The Kolmogorov microscales, being a measure of the smallest eddies in the turbulent flow, proved to be a good reference for the maximum sizes of the fragile macroflocs (Van Leussen 1997). Only when the floc growth is very low, this ultimate limit will not be reached, such as in the case of low sediment concentrations or a sediment with a low cohesivity (low effective collision efficiency factor).

From Fig. 12, it must be concluded that there is no distinct effect of the suspended sediment concentration on the sizes of the macroflocs and consequently also not on the settling velocities. The turbulent structure limits the floc growth. The ultimate size is the combined effects of this floc growth-limiting process and the floc growth-stimulating factors such as cohesivity, turbulence, suspended sediment concentration, and the size distribution of the resuspended sediment particles. It does not mean that the suspended sediment concentration is not an important factor, but only that other factors may be of equal importance. This explains the longitudinal distribution of the size and settling velocities of the macroflocs along the estuary.

\section{Conclusions}

Most characteristic of the fine-grained sediment behavior under tidal action are the so-called erosion/sedimentation cycles. The suspended sediment concentrations are primarily a result of vertical movements of the sediment. This means that the suspended sediment distribution is particularly governed by local phenomena.

Analysis of the video recordings, obtained from VIS measurements, showed that large fragile aggregates, the socalled macroflocs, govern the vertical fine-grained sediment
Fig. 12 Longitudinal variation of the sizes $D_{\mathrm{h}}$ of the macroflocs, the suspended sediment concentration $(C)$, and the salinity $(S)$, all measured at the same level $(2.80 \mathrm{~m}$ below the water surface) during high flow currents (average of flood and ebb)

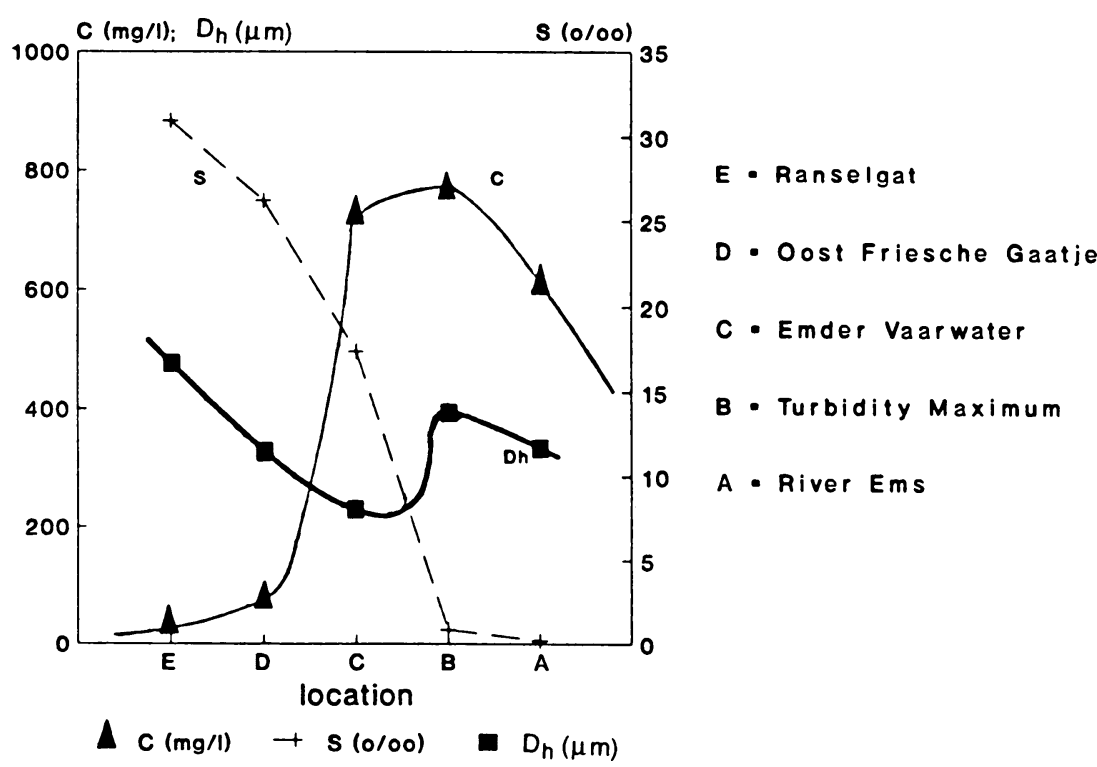


movements during a tidal cycle. This holds even in cases where the numbers of these flocs are relatively small.

VIS measurements in the Ems Estuary during a complete tidal cycle showed an abundance of large flocs shortly after maximum flow velocity. Generally, these macroflocs had sizes in the range of 200 to $700 \mu \mathrm{m}$, sometimes more than $1 \mathrm{~mm}$, and survived high current velocities. The settling velocities were in the range of 0.5 to $8 \mathrm{~mm} / \mathrm{s}$.

The suspended sediment concentration is an important parameter in determining the settling velocity of mud flocs, but particularly at low levels of turbulence. At high levels of turbulence, the limiting properties of turbulence dominate. This explains why no effect was observed of the suspended sediment concentration on the size and settling velocities of the macroflocs in the Ems Estuary. Even at low suspended sediment concentrations, flocculation was observed. This is understandable for situations where the conditions are sufficiently favorable, as was observed in the seaward part of the Ems Estuary.

Whereas the suspended sediment concentration and turbulence affect the floc growth principally through the increased number of collisions per unit of time, the physico-chemical and biological parameters affect the floc growth principally through their effect on the efficiency of the collisions. To quantify this efficiency, the concept of "flocculation ability" proved to be useful. The electrophoretic mobility EM seemed to be a good indicator of the flocculation ability. Its value, where significant flocculation may be expected, depends on the composition and concentration of dissolved organic substances that form bridges between the suspended sediment particles, for example, polysaccharides. There is a need for more insight into the quantitative effects of such carbohydrates for a variety of salinities. SEM photographs showed that the surfaces of the flocs were covered with fibers and threads of microorganisms, which also may contribute to a higher efficiency of the collisions. The SEM photographs also showed that the sizes of the microflocs, being the building blocks of the larger macroflocs, may vary significantly along the estuarine axis. A significant increase was observed in the seaward direction.

On the basis of these varying properties, the flocculation ability was shown to vary almost an order of magnitude along the estuarine axis. These higher flocculation abilities in the direction of higher salinities are responsible for the increase of the sizes of the macroflocs in the seaward direction, notwithstanding a substantial decrease of the suspended sediment concentration.

It should be noticed that, in the estuarine system, several factors work at the same time. This makes it very difficult to draw conclusions for the contribution of each individual factor. More insight is needed in the contribution of each of the separate parameters to the flocculation ability, for example, the biological processes.
The analysis of the sediment transports at the five measuring locations showed that time lags between current velocity and suspended sediment concentration contribute significantly to the tidally averaged transports. They demonstrate that the short-term vertical transports are the building blocks for the ultimate long-term transports. This means that settling behavior of the mud flocs, together with other relevant processes, such as resuspension and vertical mixing, plays a significant role in fine-grained sediment transport. This settling behavior was predominantly governed by the fragile macroflocs.

Open Access This article is distributed under the terms of the Creative Commons Attribution Noncommercial License which permits any noncommercial use, distribution, and reproduction in any medium, provided the original author(s) and source are credited.

\section{References}

Andersen TJ, Pejrup M, Nielsen AA (2006) Long-term and highresolution measurements of bed level changes in a temperate, microtidal coastal lagoon. Mar Geol 226:115-125

Bass SJ, Manning AJ, Dyer KR (2005) Preliminary findings from a study of the upper reaches of the Tamar Estuary, UK, throughout a complete tidal cycle: Part I. Linking sediment and hydrodynamic cycles. In: Maa JP-Y, Sanford LP, Schoellhamer DH (eds) Coastal and Estuarine Fine Sediment Processes. Elsevier Science, Amsterdam, pp 1-14

De Jonge VN (1995) The Ems Estuary, The Netherlands. Chapter 7 in: A.J. McComb (Ed.) Eutrophic Shallow Estuaries and Lagoons. CRC Press: $81-107$

De Jonge VN, Brauer VS (2006) The Ems estuary. Changes in functioning and structure of a system under pressure. University of Groningen, Groningen, $\mathrm{p} 100$

Doxaran D, Froidefond J, Castaing P, Babin M (2009) Dynamics of the turbidity maximum zone in a macrotidal estuary (the Gironde, France): Observations from field and MODIS satellite data. Estuar Coast Shelf Sci 81(3):321-332

Dyer KR, Cornelisse J, Dearnaley MP, Fennessy MJ, Jones SE, Kappenberg J, McCave IN, Pejrup M, Puls W, van Leussen W, Wolfstein K (1996) A comparison of in situ techniques for estuarine floc settling velocity measurements. J Sea Res 36(1/2):15-29

Dyer KR, Bale AJ, Christie MC, Feates N, Jones S, Manning AJ (2002a) The turbidity maximum in a mesotidal estuary, the Tamar Estuary, UK. Part I: Dynamics of suspended sediment. In: Winterwerp JC, Kranenburg C (eds) Fine Sediment Dynamics in the Marine Environment - Proceedings in Marine Science 5. Amsterdam: Elsevier, Amsterdam, pp 203-218

Dyer KR, Bale AJ, Christie MC, Feates N, Jones S, Manning AJ (2002b) The turbidity maximum in a mesotidal estuary, the Tamar Estuary, UK. Part II: The floc properties. In: Winterwerp JC, Kranenburg C (eds) Fine Sediment Dynamics in the Marine Environment Proceedings in Marine Science 5. Elsevier, Amsterdam, pp 219-232. ISBN 0-444-51136-9

Eisma D, Dyer KR, van Leussen W (1997) The in-situ determination of the settling velocities of suspended fine-grained sediment - a review. In: Burt N, Parker R, Watts J (eds) Cohesive Sediments. John Wiley \& Sons, New York, pp 17-44 
Fennessy MJ, Dyer KR, Huntley DA (1994) Size and settling velocity distributions of flocs in the Tamar Estuary during a tidal cycle. Netherlands J Aquatic Ecol 28:275-282

Gibbs RJ (1977) Clay mineral aggregation in the marine environment. J Sed Petrol 47:237-243

Hunter KA (1980) Microelectrophoretic properties of natural surface-active organic matter incoastal seawater. Limnol Oceanogr 25(5):807-822

Hunter KA, Liss PS (1982) Organic matter and the surface charge of suspended particles in estuarine waters. Limnol Oceanogr 27 (2):322-335

Le Hir P, Ficht A, Jacinto RS, Lesueur P, Dupont J, Lafite R, Brenon I, Thouvenin B, Cugier P (2001) Fine sediment transport and accumulations at the mouth of the Seine estuary (France) Estuaries and Coasts, Vol. 24, No. 6: 950-963

Liu, Qui-zhen (2006) Effects of $\mathrm{AlCl} 3, \mathrm{MgCl} 2$ and humus on the flocculation of fine sediments in the high-turbid system of the Changiiang Estuary. Journal of Sediment Research No. 6

Liu, Qui-zhen (2007) Flocculation process of fine-grained sediments by the combined effect of salinity and humus in the Changjiang Estuary. Acta Oceanolog Sin 26(1):140-149

Lumborg U, Pejrup M (2006) Modelling of cohesive sedimenttransport in a tidal lagoon - an annual budget. Mar Geol 218:1-16

Maa JP-Y, Kwon J (2007) Using ADV for cohesive sediment settling velocity measurements. Estuar Coast Shelf Sci 73(1-2):351-354

Manning AJ, Bass SJ (2006) Variability in cohesive sediment settling fluxes; Observations under different estuarine tidal conditions. Mar Geol 235(1-4):177-192

Manning AJ, Dyer KR (2002) The use of optics for the in situ determination of flocculated mud characteristics. J Opt A: Pure Appl Opt 4:S71-S81

Manning AJ, Martens C, de Mulder T, Vanlede J, Winterwerp JC, Graham GW (2007) Mud floc observations in the turbidity maximum zone of the Scheldt estuary during neap tides. J. Coast. Res. Spec. Issue(50): 832-836

Mantovanelli A, Ridd PV (2006) Devices to measure settling velocities of cohesive sediment aggregates: a review of the in situ technology. J Sea Res 56(3):199-226

Martin JM, Mouchel JM, Jadnacak-Biscan J (1986) Surface properties of particles at the land-sea boundary. In: Lasserre P, Martin JM (eds) Biogeochemical Processes at the Land-Sea Boundary. Elsevier, New York, pp 53-71

Nakagawa Y, Yoshida H (2008) Field observation and modeling of suspended fine sediment load in Ariake Bay. Chapter 12. In: Kusuda T, Yamanishi H, Spearman J, Gailani JZ (eds) Sediment and Ecohydraulics, Proceedings in Marine Science 9. Elsevier Science, Amsterdam, pp 155-163

Neihof RA, Loeb GI (1972) The surface charge of particulate matter in seawater. Limnol Oceanogr 17(1):7-16

Neihof RA, Loeb GI (1974) Dissolved organic matter in seawater and the electric charge of immersed surfaces. J Mar Res 32:5-12

Postma H (1967) Sediment transport and sedimentation in the marine environment. In: Lauff GH (ed) Estuaries. American Association for the Advancement of Science. Publication 83, Washington DC, pp $158-186$
Schoellhamer DH (2002) Variability of suspended-sediment concentration at tidal to annual time scales in San Francisco Bay, USA. Cont Shelf Res 22(11):1857-1866

Sondy I, Pravdic V (2002) Electrokinetic investigations of clay mineral particles. Chapter 27. In: Delgado ÁV (ed) Interfacial electrokinetics and electrophoresis. Surfactant Science, vol 106. Dekker, New York, pp 773-798

Tattersall GR, Elliott AJ, Lynn NM (2003) Suspended sediment concentrations in the Tamar estuary. Estuar Coast Shelf Sci 57(4):679-688

van Leussen W (1991) Fine sediment transport under tidal action. Geo-Mar Lett 11:119-126

van Leussen W (1994) Estuarine Macroflocs and their Role in Finegrained Sediment Transport. PhD Thesis University of Utrecht, Utrecht, pp. 488

van Leussen W (1996a) Erosion/sedimentation cycles in the Ems Estuary. Arch Hydrobiol Spec Issues Advanc Limnol 47:179-193

van Leussen W (1996b) The RWS field settling tube. J Sea Res 36(1/2):8386

van Leussen W (1997) The kolmogorov microscale as a limiting value for the floc sizes of suspended fine-grained sediments in estuaries. In: Burt N, Parker R, Watts J (eds) Cohesive Sediments. John Wiley \& Sons, Chichester UK, pp 45-62

van Leussen W (1999) Variations of the settling velocity of suspended fine-grained sediment in estuaries. Journal of Sea Research (special volume: Fine particles in the sea; pathways, processes, puzzles - a tribute to Doeke Eisma). Volume 41, 1/2, p. 109-118

van Leussen W, Cornelisse JM (1993a) The determination of the sizes and settling velocities of estuarine flocs by an underwater video system. Neth J Sea Res 31(3):231-241

van Leussen W, Cornelisse JM (1993b) The role of large aggregates in estuarine fine-grained sediment dynamics. In: Mehta AJ (ed) Nearshore and Estuarine Cohesive Sediment Transport. Coastal and estuarine studies No. 42. American Geophysical Union, Washington DC, pp 75-91

van Leussen W, Cornelisse JM (1996) The underwater videosystem VIS. Journal of Sea Research, 87-91

Vinzon SB, Mehta AJ (2001) Boundary layer effects due to suspended sediment in the Amazon River estuary. In: McAnally AJ Mehta WH, Mehta AJ (eds) Coastal and Estuarine Fine Sediment Processes. Proceedings in Marine Science 3, Elsevier, Amsterdam, pp 359-372

Wai OWH, Wang CH, Li YS, Li XD (2004) The formation mechanisms of turbidity maximum in the Pearl River estuary, China. Marine Pollution Bulletin, Vol. 48. Issues 5-6:441448

Winterwerp JC, van Kesteren GM (2004) Introduction to the Physics and Cohesive Sediment in the Marine Environment. Developments in Sedimentology 56. Elsevier, Amsterdam, p 466

Winterwerp JC, Manning AJ, Martens C, de Mulder T, Vanlede J (2006) A heuristic formula for turbulence-induced flocculation of cohesive sediment. Est Coast Shelf Sci 68(1-2):195-207

Zhong Shi, Zhou HJ, Eittreim SL, Winterwerp JC (2003) Settling velocities of fine suspended particles in the Changjiang Estuary, China. J Asian Earth Sci 22(3):245-251 